\title{
Regulator of telomere length 1 (RTEL1) mutations are associated with heterogeneous pulmonary and extra-pulmonary phenotypes
}

\author{
Raphael Borie (ib) ${ }^{1,2}$, Diane Bouvry ${ }^{3}$, Vincent Cottin (ib) ${ }^{4}$ Clement Gauvain², \\ Aurélie Cazes ${ }^{2,5}$, Marie-Pierre Debray ${ }^{2,6}$, Jacques Cadranel $^{7}$, \\ Philippe Dieude (10) 2,8, Tristan Degot $^{10}{ }^{\text {, Stephane Dominique }}{ }^{11}$, \\ Anne Sophie Gamez ${ }^{12}$, Madeleine Jaillet ${ }^{2}$, Pierre-Antoine Juge ${ }^{8}$, \\ Arturo Londono-Vallejo (10 ${ }^{13}$, Arnaud Mailleux², Hervé Mal ${ }^{2,14}$, \\ Catherine Boileau $\mathbb{1}^{9,15}$, Christelle Menard ${ }^{15}$, Hilario Nunes ${ }^{3}$, Gregoire Prevot ${ }^{16}$, \\ Sebastien Quetant ${ }^{17}$, Patrick Revy ${ }^{18}$, Julie Traclet ${ }^{7}$, Lidwine Wemeau-Stervinou ${ }^{19}$, \\ Marie Wislez ${ }^{20}$, Caroline Kannengiesser $\mathbb{1}^{2,9,15}$ and Bruno Crestani ${ }^{1,2,9}$
}

@ERSpublications

RTEL1 mutations are associated with heterogeneous lung phenotypes with limited and heterogeneous extra-respiratory manifestations http://ow.ly/1Ssr30mCZjx

Cite this article as: Borie R, Bouvry D, Cottin V, et al. Regulator of telomere length 1 (RTEL1) mutations are associated with heterogeneous pulmonary and extra-pulmonary phenotypes. Eur Respir J 2019; 53: 1800508 [https://doi.org/10.1183/13993003.00508-2018].

ABSTRACT Regulator of telomere length 1 (RTEL1) mutations have been evidenced in 5-9\% of familial pulmonary fibrosis; however, the phenotype of patients with interstitial lung disease (ILD) and RTEL1 mutations is poorly understood.

Whole exome sequencing was performed in 252 probands with ILD and we included all patients with ILD and RTEL1 mutation. RTEL1 expression was evaluated by immunochemistry in the lungs of controls, as well as in RTEL1 and telomerase reverse transcriptase (TERT) mutation carriers.

We identified 35 subjects from 17 families. Median age at diagnosis of ILD was 53.1 years (range 28.0-80.6). The most frequent pulmonary diagnoses were idiopathic pulmonary fibrosis $(\mathrm{n}=20,57 \%)$, secondary ILD $(n=7,20 \%)$ and unclassifiable fibrosis or interstitial pneumonia with autoimmune features $(n=7,20 \%)$. The median transplant-free and overall survival periods were 39.2 months and 45.3 months, respectively. Forced vital capacity at diagnosis was the only factor associated with decreased transplant-free survival. Extra-pulmonary manifestations were less frequent as compared to other telomere-related gene mutation carriers. A systematic analysis of the literature identified 110 patients with ILD and RTEL1 mutations (including this series) and confirmed the heterogeneity of the pulmonary phenotype, the prevalence of non-idiopathic diseases and the low prevalence of extra-pulmonary manifestations.

Immunohistochemistry showed that RTEL1 was expressed by bronchial and alveolar epithelial cells, as well as by alveolar macrophages and lymphocytes, but not by fibroblasts. 


\section{Introduction}

Almost $10 \%$ of the patients with idiopathic pulmonary fibrosis (IPF) present a first-degree relative with interstitial lung disease (ILD) suggesting a common genetic predisposition [1]. Rare genetic variants reported to date involve mainly telomere related genes (TRGs) [2]. TRGs are involved in telomere maintenance, controlling addition of repeated DNA sequences in the telomere region of chromosomes and thereby protecting the chromosomes from loss of material during mitosis [3]. Among TRG mutations, heterozygous telomerase reverse transcriptase (TERT) mutations are the most frequently observed, being detected in approximately $15 \%$ of the cases of familial pulmonary fibrosis, whereas heterozygous mutations in regulator of telomere length 1 (RTEL1), poly(A)-specific ribonuclease (PARN), telomerase RNA component (TERC), dyskerin pseudouridine synthase 1 (DKC1), TERF1 interacting nuclear factor 2 (TINF2) and nuclear assembly factor 1 ribonucleoprotein (NAF1) are much rarer [4-7]. Most patients with TERT or TERC mutations harbour shortened telomeres and display extrapulmonary diseases (skin, haematological or liver diseases), usually labelled as "(short) telomere syndrome” [3].

RTEL1 is a DNA helicase playing roles in DNA replication, genome stability, DNA repair and telomere maintenance [8]. Bi-allelic mutations in RTEL1 have been reported in patients with Hoyeraal-Hreidarsson syndrome (see the Online Mendelian Inheritance in Man (OMIM) Catalogue; entry \#305000, www.omim.org/), a severe variant of short telomere syndrome characterised by early-onset bone marrow failure, immunodeficiency and developmental defects associated with abnormally short telomeres, as well as myelodysplasia and liver disease [9-14]. Heterozygous RTEL1 mutations are also detected in 5-9\% of patients with familial forms of ILD [15-18]. Little is known about specific sites of pulmonary RTEL1 expression in fibrotic lungs. The aim of the study was to describe the phenotype of patients with ILD who were carriers of RTEL1 heterozygous mutation, from our genetic laboratory and from the literature, and to evaluate lung RTEL1 expression in those patients.

\section{Methods}

Subjects

This is a retrospective, observational, non-interventional study. For this study, we included all patients with confirmed ILD and RTEL1 mutation.

RTEL1 mutation carriers were identified by whole exome sequencing performed in two different cohorts and considered as pathogenic according to the American College of Genetics and Genomics guidelines and the European Society for Human Genetics recommendations [16, 19, 20]. The first cohort included 151 probands with suspected monogenic pulmonary fibrosis (familial or with extrapulmonary disease) without TERT or TERC pathogenic mutation, while the second cohort included 101 patients with ILD associated with rheumatoid arthritis (RA) $[16,20]$.

All patients signed informed consent for genetic analysis including research purposes. The clinical charts of the patients and their relatives were reviewed and data were collected on a standardised and anonymous collection form. Clinical data, chest computed tomography (CT) scan and lung histological pattern were systematically reviewed, analysed by multidisciplinary team discussion and classified according to the 2011 statement for IPF and the 2013 classification of idiopathic interstitial pneumonias [21, 22]. Patients with a possible usual interstitial pneumonia (UIP) pattern on CT scan were reclassified to probable or indeterminate for UIP pattern according to the Fleischner Society criteria and without available histology were given a working diagnosis of IPF or a diagnosis of unclassifiable fibrosis (UnF) after multidisciplinary discussion [23]. Methods of genetic analysis are detailed in the supplementary material. This study was

Affiliations: 'Service de Pneumologie A, Hôpital Bichat, AP-HP, DHU FIRE, Paris, France. ${ }^{2}$ Unité 1152 , INSERM, Université Paris Diderot, Paris, France. ${ }^{3}$ Service de Pneumologie, Hôpital Avicenne, AP-HP, Bobigny, France. ${ }^{4}$ Service de Pneumologie, Hôpital Louis Pradel, Université Claude Bernard Lyon 1, Lyon, France. ${ }^{5}$ Service d'Anatomopathologie, Hôpital Bichat, AP-HP, Paris, France. ${ }^{6}$ Service de Radiologie, Hôpital Bichat, AP-HP, Paris, France. ${ }^{7}$ Service de Pneumologie, Hôpital Tenon, AP-HP, Paris, France. ${ }^{8}$ Service de Rhumatologie, Hôpital Bichat, AP-HP, Paris, France. ${ }^{9}$ Université Paris Diderot, Paris, France. ${ }^{10}$ Service de Pneumologie, CHU Strasbourg, Strasbourg, France. ${ }^{11}$ Dept of Pneumology, Rouen University Hospital, Rouen, France. ${ }^{12}$ Service de Pneumologie, CHU Montpellier, Montpellier, France. ${ }^{13}$ UMR 3244 (Telomere and Cancer Lab), CNRS, Institut Curie, PSL Research University, Sorbonne Universités, Paris, France. ${ }^{14}$ Service de Pneumologie B, Hôpital Bichat, AP-HP, Paris, France. ${ }^{15}$ Laboratoire de Génétique, Hôpital Bichat, AP-HP, Paris, France. ${ }^{16}$ Service de Pneumologie, Hôpital Larrey, Toulouse, France. ${ }^{17}$ Service de Pneumologie, CHU de Grenoble, Grenoble, France.

${ }^{18}$ UMR 1163 (Laboratory of Genome Dynamics in the Immune System), INSERM, Imagine Institute, Paris Descartes-Sorbonne Paris Cité University, Paris, France. ${ }^{19}$ Service de Pneumologie, Centre de Compétence des Maladies Pulmonaires Rares, CHRU de Lille, Lille, France. ${ }^{20}$ Service de Pneumologie, Unité d'Oncologie Thoracique, Hôpital Cochin, Hôpitaux Universitaires Paris Centre, AP-HP, Paris, France.

Correspondence: Raphael Borie, Service de Pneumologie A, Hôpital Bichat, 46 rue Henri Huchard, 75877 Paris CEDEX 18, France. E-mail: raphael.boriedaphp.fr 
approved by the local ethics committee (CPP Ile de France 1, no. 0811760) and written informed consent was obtained from all subjects.

\section{Review of the literature}

We searched Web of Science on December 01, 2017 using the search terms "pulmonary fibrosis" and "RTEL1" with no restrictions on publication date or language. Full articles were retrieved for the 18 references obtained. All the patients with pulmonary fibrosis and available clinical data were then included in this review. The patients reported by STUART et al. [15] were considered to be extensively reported by NEWTON et al. [7]. Five articles with clinical data and the present cohort were finally conserved for analysis $[7,10,14,17]$.

\section{Immunohistochemistry}

Lung samples were obtained at the time of lung transplantation from three IPF patients with RTEL1 mutation, three IPF patients with TERT mutation and five IPF patients without any detected mutation. Control lung samples were non-disease-involved segments from three patients who were undergoing lung surgery for removal of a primary lung tumour.

Paraffin-embedded sections were treated as previously described [24]. For immunohistochemistry, we used an in house developed and previously reported anti-RTEL1 antibody, the specificity of which has been confirmed using CRISPR-Cas9 against the RTEL1 gene [25]. Briefly serial 7- $\mu$ m thick paraffin-embedded tissue sections were deparaffinised and rehydrated. Antigen retrieval was performed in citrate buffer $\left(1.8 \mathrm{mM}\right.$ citric acid, $8.3 \mathrm{mM}$ sodium citrate, $\mathrm{pH}$ 6) in a water bath at $97{ }^{\circ} \mathrm{C}$ for $40 \mathrm{~min}$. Tissue sections were blocked with $3 \%$ bovine serum albumin (BSA) for $1 \mathrm{~h}$ at room temperature, incubated with the homemade primary antibody overnight at $4{ }^{\circ} \mathrm{C}$ and then assayed with a Vectastain $\mathrm{ABC}$ alkaline phosphatase kit (Vector Labs, Les Uis, France) and fast red substrate (DakoCytomation, Glostrup, Denmark) [10]. To test the specificity of immunostaining, antibodies were replaced by an isotype-matched control. Light microscopy images were acquired with the use of a DM400B light microscope equipped with a DFC420 CDD camera (Leica Microsystems, Nanterre, France).

RTEL1 expression was anonymously analysed patient by patient by an experienced thoracic pathologist, blinded from the genetic analysis, using a semi-quantitative ladder.

\section{Statistical analysis}

Continuous variables were expressed as median (range) and were compared by Mann-Whitney U-test. Categorical variables were expressed as $\mathrm{n}(\%)$ and were compared by Chi-squared or Fisher exact tests where appropriate. Transplant-free survival was estimated with the Kaplan-Meier method for censored data and Cox models were used to analyse which factors at the time of diagnosis were associated with transplant-free survival. A group of patients with ILD carrying a TERT or TERC mutation, as identified in the laboratory and described previously, was used as a control group [26]. All tests were two-sided with $\mathrm{p}<0.05$ indicating statistical significance. A linear mixed model was used to derive the annual decline of forced vital capacity (FVC) [27]. Analyses involved the use of GraphPad Prism V6 (GraphPad Software, LaJolla, CA, USA) and R software version 2.15.2 (The R Project for Statistical Computing; www.r-project.org/).

\section{Results}

Patients

We identified 35 patients from 17 independent families with ILD and a pathogenic RTEL1 mutation. The main clinical data are presented in figures 1 and 2 and tables 1 and 2. Complementary clinical data are provided in the supplementary material. Mean age was unusually young for a population of lung fibrosis patients (53 years) within a range extending from 28 years to 80 years. A UIP pattern was prominent on high-resolution computed tomography (HRCT) in 25 out of 31 patients (81\%) and IPF was the most frequent diagnosis (57\%). However, an alternative diagnosis was not rare, including UnF or interstitial pneumonia with autoimmune features (IPAF) (seven patients, 17.2\%), RA-ILD (four patients, 11.4\%), chronic hypersensitivity pneumonitis (HP; two patients, 5.7\%), sarcoidosis (Sarc; one patient) and pneumoconiosis (PC; one patient).

Eight patients $(22.8 \%)$ reported premature hair graying (at less than 30 years of age) without any other cutaneous sign of dyskeratosis congenita (DC). Complete blood count and liver function tests were available for 32 patients. Four patients (12.5\%) had a low platelet count $\left(<150 \mathrm{G} \cdot \mathrm{L}^{-1}\right)$ and five patients $(15.6 \%)$ had red blood cell macrocytosis $\left(>100 \mu \mathrm{m}^{3}\right)$. Four patients showed repeated elevated liver enzymes $(11.4 \%)$ and further diagnoses of autoimmune hepatitis $(n=1)$, alcoholic liver cirrhosis $(n=1)$, alcoholic and post-hepatitis $C$ liver cirrhosis $(n=1)$ and non-alcoholic steatohepatitis $(n=1)$ were made. 


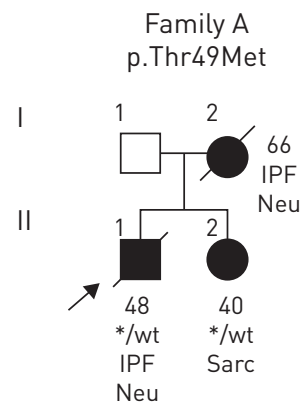

Family A

Family $\mathrm{E}$ c. 2226-1G>C

I

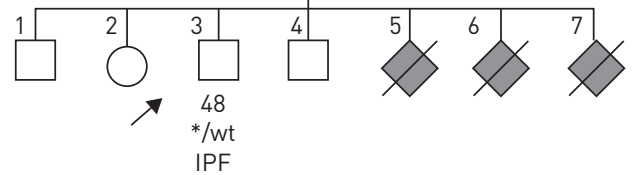

Family C

p.Phe964Leu

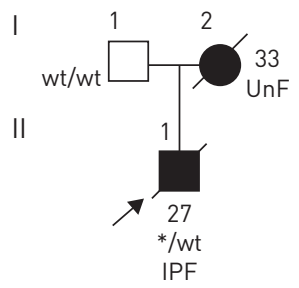

II

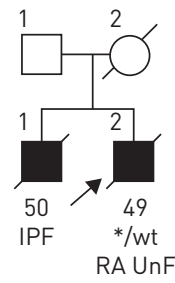

Family D

p.Gln1165Profs*22

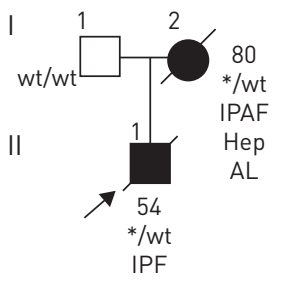

Family $\mathrm{H}$

c.3556_3559delAGAC

।

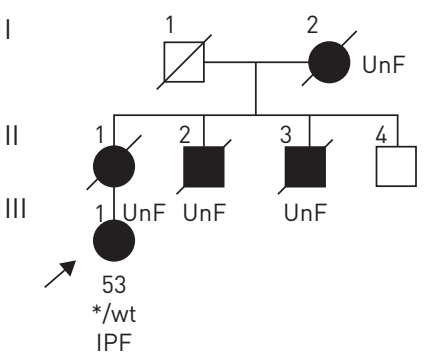

Family $\mathrm{P}$ p.Trp1140*

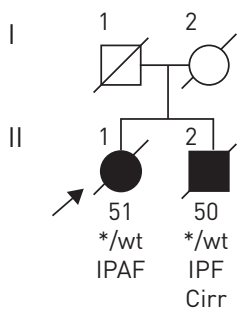

Family I

p.Arg986*

I

II

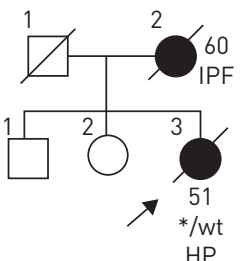

Family $G$

c.1228_1266+39del78

।

II

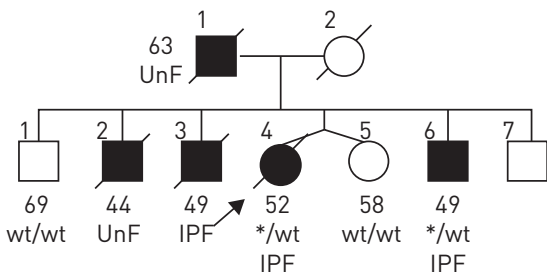

Family J

p.Arg957Trp

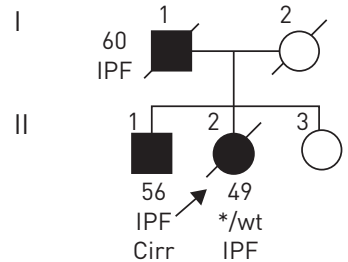

Family Q p.Glu966Argfs*

Family U p.Thr48Met

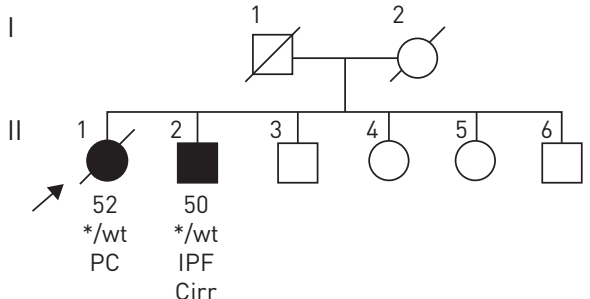

FIGURE 1 Pedigree of 12 families featuring segregation of familial interstitial lung disease (ILD) and regulator of telomere length 1 (RTEL1) heterozygous mutation. Five RTEL1 mutation carrying patients had no family members with lung disease, extrapulmonary signs of telomere disease, or known carrier of the RTEL1 mutation. Individuals with pulmonary fibrosis are indicated by black symbols. Individuals in grey are deceased with no possibility of knowing the cause of death. Heterozygosity for the mutation is indicated by */wt (with wt for wild-type status and * for the presence of the variant). When indicated, numbers are ages at diagnosis of ILD. IPF: idiopathic pulmonary fibrosis; Neu: neutropenia; Sarc: sarcoidosis; RA: rheumatoid arthritis; IPAF: interstitial pneumonia with autoimmune features; AL: acute leukaemia; Hep: hepatitis; HP: hypersensitivity pneumonitis; Cirr: cirrhosis; An: anaemia; PC: pneumoconiosis; UnF: unclassifiable fibrosis.

Telomere length was available for 17 patients and the median value was $6.5 \mathrm{~kb}$ (4.4-10.8). Telomere length was below the tenth percentile $(<10$ th) in six patients $(35 \%)$. Median telomere length of the patients from the second generation was similar to that of the patients from the first generation $(6.5 \mathrm{~kb}$ versus $8.4 \mathrm{~kb}$, $\mathrm{p}=0.19)$. 

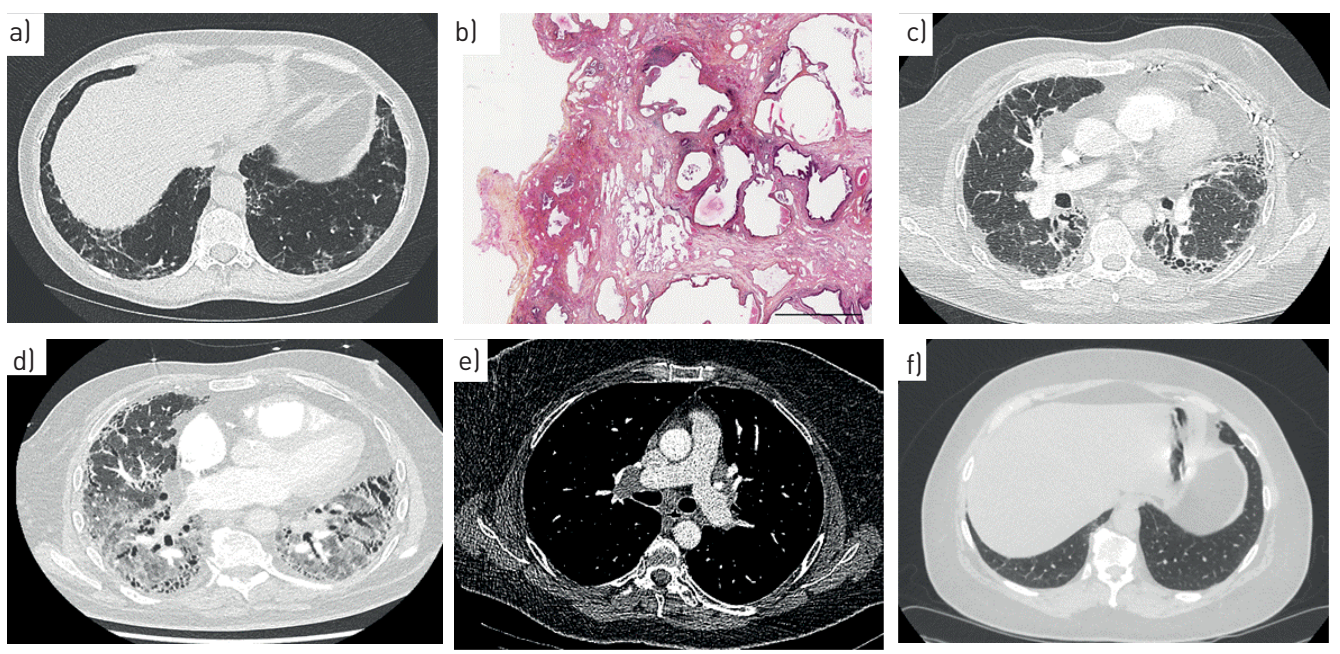

FIGURE 2 Spectrum of interstitial lung disease (ILD) in patients with heterozygous regulator of telomere length 1 (RTEL1) mutations. Details are as follows: a) a 58 year-old female smoker (subject II, 3, family I) with an indeterminate usual interstitial pneumonia (UIP) pattern on computed tomography (CT) scan. Histology showed a possible UIP pattern with rare granuloma (not provided). She was exposed to birds and precipitating antibodies to birds were positive. A diagnosis of hypersensitivity pneumonitis (HP) was made and the pulmonary function tests (PFTs) remained stable during follow-up; b) a 43 year-old male smoker (subject II, 3, family E) with an initial UIP pattern on CT scan (not provided). A diagnosis of idiopathic pulmonary fibrosis (IPF) was made and his pulmonary function declined progressively. He received lung transplantation 6 years after ILD diagnosis. Histology of the explant confirmed an atypical UIP pattern; $c$ and d) a 54 year-old male smoker (subject II, 1, family D) with a typical UIP pattern on CT scan at ILD diagnosis (c) leading to a diagnosis of IPF. The patient presented an acute exacerbation of IPF with superimposed ground glass opacities on CT scan (d) and eventually died; e and f) a 40 year-old female smoker (subject II, 2, family A) with mediastinal adenopathy in the mediastinal window of a contrast-enhanced CT scan (e) and ground glass opacities with lower predominance in the parenchymal window (f). Histology of adenopathy revealed well-formed non-necrotising granulomas and a diagnosis of sarcoidosis was made.

\section{Evolution and survival}

Twenty-eight patients received a specific treatment for the ILD, as follows: steroids ( $\mathrm{n}=23)$, immunosuppressants $(\mathrm{n}=11)$, antifibrotics $(\mathrm{n}=11)$ and $N$-acetyl cysteine $(\mathrm{n}=2)$ (table 3). Seven patients did not receive any treatment. Pulmonary improvement (as assessed by pulmonary function test (PFT) or decreased oxygen requirement) was achieved with steroids in four patients (two patients with nonspecific interstitial pneumonia (NSIP) and two patients with acute exacerbation of IPF) (figure 3). Due to the limited number of patients who received antifibrotic therapy, an assessment of antifibrotic therapy efficacy was not feasible. The mean decline of FVC for the whole population was $140.5 \mathrm{~mL} \cdot y e \mathrm{r}^{-1}(-229.9$; $-51.21)$, corresponding to a decrease of $4.5 \%$ per year $(-7.3 ;-1.6)$ of the predicted value.

After a median follow-up of 47.3 months, 25 patients had died and four patients had undergone lung transplantation. The median transplant-free survival period was 39.2 months and the overall survival period was 45.3 months. One patient died of lung cancer and two after lung transplantation (due to haematological complications and chronic lung rejection). In the other 22 patients, death was related to lung fibrosis progression. On univariate analysis, FVC measured at diagnosis was the only factor that was associated with decreased transplant-free survival $(\mathrm{p}=0.009)$ (table 4).

\section{Genetics}

Herein we report 11 new families carrying RTEL1 mutations, while four occurences of familial pulmonary fibrosis (families A, B, C, D) and two patients with sporadic RA-ILD were reported previously $[16,20]$. Altogether 13 different heterozygous RTEL1 mutations were identified (table 2), including eight previously reported mutations and five never previously reported mutations (bold in table 2) $[16,20,28]$.

Among the five new mutations, three result in a premature stop codon (c.2896del, c.3420C $>\mathrm{A}$ and c.3556_3559delAGAC) and two are predicted to interfere with RTEL1 splicing (c.1228_1266+39del78, c.1266+3A $>$ G and c.2266-1G>C). No variant within another known TRG was evidenced in any of the families.

\section{Review of the literature}

Including this series and without the patients reported by STUART et al. [15], we identified 110 patients with ILD and RTEL1 mutations in five publications as of December 01, 2017 [7, 10, 14, 17]. The median 


\section{TABLE 1 Main characteristics of the patients at diagnosis $(n=35)$}

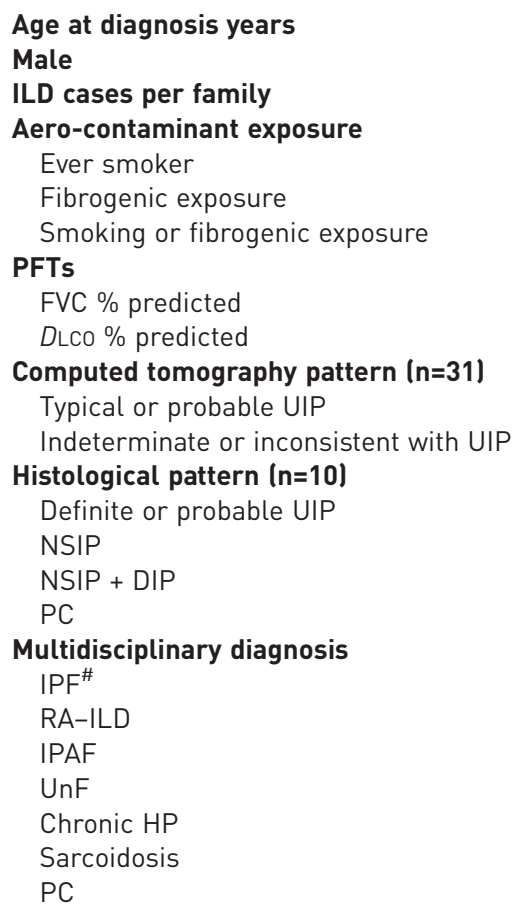

$53.1(28.0-80.6)$

$21(60.0)$

$3(1-5)$

Data are presented as $\mathrm{n}, \mathrm{n}(\%)$ or median (range). ILD: interstitial lung disease; PFT: pulmonary function test; FVC: forced vital capacity; DLCO: diffusing capacity of the lung for carbon monoxide; UIP: usual interstitial pneumonia; NSIP: nonspecific interstitial pneumonia; DIP: desquamative interstitial pneumonia; PC: pneumoconiosis; IPF: idiopathic pulmonary fibrosis; RA: rheumatoid arthritis; IPAF: interstitial pneumonia with autoimmune features; UnF: unclassifiable fibrosis; HP: hypersensitivity pneumonitis. \#: IPF, or probable IPF or possible IPF diagnosis based on CT scan and histology. Patients with probable UIP on CT scan without histology, but with a working diagnosis of IPF after multidisciplinary discussion, are classified as IPF.

age at ILD diagnosis was 60.0 years (0.7-82), there was a predominance of males $(60.9 \%)$ and $51 \%$ of the patients were current or past smokers (table 5). Only one study reported genetic anticipation [7].

The most frequent pattern was definite UIP (82.6\%) and the most frequent pulmonary diagnosis was IPF (72.2\%). Other diagnoses were IPAF or connective tissue disease (CTD)-ILD (7.2\%), UnF (6.3\%), chronic HP (4.5\%), pleuroparenchymal fibroelastosis (PPFE; 1.8\%), Sarc (0.9\%), PC (0.9\%) and unknown (UNK; $6.2 \%)$. Significant emphysema was reported in $24.4 \%$ of patients and three patients with lung cancer were reported $(2.7 \%)$.

No patient with haematological or hepatic disease without ILD has been reported in any subject of a family with pulmonary fibrosis and heterozygous mutation of RTEL1. In patients with ILD, thrombocytopenia was reported in $8.1 \%$ of cases, macrocytosis in $18.3 \%$ of cases and anaemia $(\mathrm{An})$ in $16.3 \%$ of cases. Hepatic disease was reported in $9.8 \%$ of cases.

\section{RTEL1 expression}

We used immunohistochemistry to analyse the cell distribution of RTEL1 in control non-fibrotic lung samples $(n=3)$, nonmutated sporadic IPF samples $(n=5)$, TERT mutated samples $(n=3)$ and RTEL1 mutated IPF samples $(\mathrm{n}=3)$ (figure 4). In control lungs, RTEL1 was detected in the cytoplasm and the nucleus of bronchial epithelial cells, alveolar macrophages and in alveolar Type-2 epithelial cells (figure 4a). In fibrotic lungs, RTEL1 was detected in bronchial epithelial cells, alveolar macrophages, hyperplastic alveolar epithelial cells and lymphocytes (particularly within lymphoid follicles) (figure 4b). RTEL1 was localised in the nucleus and in the cytoplasm in all cell types, but was not detected in fibroblastic foci or endothelial cells (figure 4c). Isotype control staining was negative (figure $4 \mathrm{f}$ ) and, using a semi-quantitative evaluation, RTEL1 expression was similar in samples with TERT or RTEL1 mutation and in sporadic IPF without mutation. 
TABLE 2 Regulator of telomere length 1 (RTEL1) variations retained as disease-associated in 17 families

\begin{tabular}{|c|c|c|c|c|c|c|c|c|c|c|c|c|c|c|}
\hline \multirow[t]{2}{*}{ Mutation } & \multicolumn{2}{|c|}{ Position of RTEL1 variation } & \multirow[t]{2}{*}{ Families" } & \multirow[t]{2}{*}{$\begin{array}{l}\text { Presence on } \\
\text { gnomAD" }\end{array}$} & \multicolumn{2}{|c|}{$\begin{array}{l}\text { In silico analysis of } \\
\text { RTEL1 variation }\end{array}$} & \multicolumn{3}{|c|}{ Segregation $^{+}$} & \multicolumn{3}{|c|}{ Telomeres ${ }^{\S}$} & \multirow[t]{2}{*}{$\begin{array}{c}\text { Haematological/liver } \\
\text { disease }^{f}\end{array}$} & \multirow{2}{*}{$\begin{array}{c}\text { Variant } \\
\text { classification } \\
{[19,26]}\end{array}$} \\
\hline & cDNA & Amino acid & & & Poly-Phen2 & $\begin{array}{c}\text { CADD } \\
\text { (PHRED) }\end{array}$ & Type & Patients & Generations & $\begin{array}{l}\text { Length } \\
\mathbf{k b}\end{array}$ & $\begin{array}{c}\text { Age } \\
\text { years }\end{array}$ & Percentile & & \\
\hline Splicing & $\begin{array}{c}\text { c. } 1228 \_1266+39 \text { del } 78, \\
\text { c. } 1266+3 A>G\end{array}$ & NA & G & Absent & NA & 32 & $\mathrm{~F}$ & 5 & 2 & 6.5 & 48 & N & & 5 \\
\hline Splicing & c. $2266-1 \mathrm{G}>\mathrm{C}$ & NA & E & Absent & NA & 22 & $\mathrm{~F}$ & 3 & 2 & 6.5 & 51 & $\mathrm{~N}$ & & 5 \\
\hline Nonsense & c.2896del & p.Glu966Argfs* & $Q$ & Absent & NA & 29.9 & $\mathrm{~F}$ & 3 & 2 & 7.0 & 73 & $\mathrm{~N}$ & $\begin{array}{c}\text { Autoimmune haemolytic } \\
\text { anaemia (1) }\end{array}$ & 5 \\
\hline Nonsense & c. $2956 \mathrm{C}>\mathrm{T}^{\# \# \#}$ & p.Arg986* & & $24(0.00008)$ & NA & 35 & $\mathrm{~s}$ & 1 & 1 & 10.8 & 57 & $\mathrm{~N}$ & & 5 \\
\hline Nonsense & c. $2956 \mathrm{C}>T^{\# \#}$ & p.Arg986* & T & $24(0.00008)$ & NA & 35 & s & 1 & 1 & 5.0 & 52 & $<10$ th & $\begin{array}{l}\text { Macrocytosis, } \\
\text { thrombocytopenia, } \\
\text { post-transplantion } \\
\text { pancytopenia (1) }\end{array}$ & 5 \\
\hline Nonsense & c. $2956 \mathrm{C}>T^{\# \#}$ & p.Arg986* & 1 & $24(0.00008)$ & NA & 35 & $\mathrm{~F}$ & 2 & 2 & NA & NA & NA & & 5 \\
\hline Nonsense & c. $3420 C>A$ & p.Trp1140* & P & Absent & Damaging & 35 & $\mathrm{~F}$ & 2 & 1 & $\begin{array}{c}7.1 \\
10.3\end{array}$ & 50 & $\mathrm{~N}$ & $\begin{array}{l}\text { Alcoholic and HCV-related } \\
\text { liver cirrhosis (1) }\end{array}$ & 5 \\
\hline Nonsense & c.3493dupC & p.Gln1165Profs*22 & $D[16]$ & Absent & NA & 25 & $\mathrm{~F}$ & 2 & 2 & $\begin{array}{l}4.4 \\
5.4\end{array}$ & $\begin{array}{l}54 \\
80\end{array}$ & $\begin{array}{l}<10 \text { th } \\
N\end{array}$ & $\begin{array}{l}\text { Autoimmune hepatitis (1) } \\
\text { Acute leukaemia (1) }\end{array}$ & 5 \\
\hline Nonsense & c.3556_3559delAGAC & $\begin{array}{l}\text { p.Gln1187Gly } \\
\text { fs*176 }\end{array}$ & $\mathrm{H}$ & Absent & NA & 11.3 & $\mathrm{~F}$ & 5 & 3 & 9.2 & 55 & $\mathrm{~N}$ & & 5 \\
\hline Missense & c. $146 C>T$ & p.Thr49Met & $A[16]$ & $1(0.000004)$ & Damaging & 28.4 & $\mathrm{~F}$ & 3 & 2 & $\begin{array}{l}4.5 \\
5.0\end{array}$ & $\begin{array}{l}47 \\
51\end{array}$ & $\begin{array}{l}<10 \text { th } \\
<10 \text { th }\end{array}$ & Neutropenia (2) & 5 \\
\hline Missense & c. $146 C>T$ & p.Thr49Met & u & $1(0.000004)$ & Damaging & 28.4 & $\mathrm{~F}$ & 2 & 1 & 6.3 & 47 & N & Alcoholic liver cirrhosis (1) & 5 \\
\hline Missense & c. $637 \mathrm{C}>\mathrm{T}$ & p.Arg213Trp & $B[16]$ & $5(0.00002)$ & Damaging & 35 & $\mathrm{~F}$ & 2 & 2 & 7.6 & 28 & $\mathrm{~N}$ & & 4 \\
\hline Missense & c. $2695 \mathrm{~T}>\mathrm{C}$ & p.Phe899Leu & $\mathrm{L}[20]$ & $1(0.000004)$ & Damaging & 25.3 & s & 1 & 1 & 5.3 & 66 & $<10$ th & & 4 \\
\hline Missense & c. $2869 \mathrm{C}>T^{\# \# \#}$ & p.Arg957Trp & $\mathrm{J}$ & $11(0.00004)$ & Damaging & 33 & $\mathrm{~F}$ & 3 & 2 & NA & NA & NA & $\begin{array}{c}\text { Alcoholic liver cirrhosis (1) } \\
\text { Thalassaemia (2) }\end{array}$ & 5 \\
\hline Missense & c. $2875 C>T$ & p.His959Tyr & $\mathrm{K}$ [20] & $1(0.000004)$ & Damaging & 15.3 & s & 1 & 1 & 8.4 & 64 & $\mathrm{~N}$ & & 3 (VUSD) \\
\hline Missense & c. $2890 \mathrm{~T}>\mathrm{C}^{\# \#}$ & p.Phe964Leu & $C[16]$ & $1(0.000004)$ & Damaging & 12.9 & $\mathrm{~F}$ & 3 & 1 & 5.7 & 48 & $<10$ th & & 5 \\
\hline Missense & c. $2890 \mathrm{~T}>\mathrm{C}^{\# \#}$ & p.Phe964Leu & 0 & $1(0.000004)$ & Damaging & 12.9 & s & 1 & 1 & 8.5 & 57 & N & Thrombocytopenia (1) & 5 \\
\hline
\end{tabular}

Data in bold are for new mutations. NA: not applicable; HCV: hepatitis C virus; N: within normal range; <10th: below 10th percentile; VUSD: variant of unknown significance with a working diagnosis of damaging. " : family details are by reference if previously reported (figure 1); ๆ: the Genome Aggregation Database (gnomAD; http://gnomad.broadinstitute.org) is a public database providing exome sequencing data from more than 120000 individuals. Data are presented as number of individuals (allele frequency); ${ }^{+}$: available segregation can be familial (F) or apparently sporadic (S). Data presented includes the number of affected patients and the number of generations involved; ${ }^{\S}$ : telomere data presented includes telomere length, age at sampling and percentile details. When available, data for several patients of the same family is presented as multiple entries in the same table cells; ${ }^{f}$ : values in parentheses are for the number of affected patients; ${ }^{\# \#}$ : previously reported. 


\begin{tabular}{|c|c|c|c|c|c|c|c|}
\hline \multirow[t]{2}{*}{ Therapy } & \multirow[t]{2}{*}{ Subjects } & \multirow{2}{*}{$\begin{array}{l}\text { Duration } \\
\text { months }\end{array}$} & \multicolumn{3}{|c|}{ Pulmonary status } & \multicolumn{2}{|c|}{ Adverse events } \\
\hline & & & Improvement & Stable & Worsening & Type & n (\%) \\
\hline Steroids & 23 & $9(2-120)$ & 4 & 8 & 11 & 0 & \\
\hline Immunosuppressants & $11^{\uparrow}$ & & & & & & \\
\hline Cyclophosphamide & 6 & $3(1-5)$ & 0 & 1 & 5 & Neutropenia & 2 (33) \\
\hline Azathioprine & 7 & $12(2-70)$ & 0 & 3 & 4 & 0 & \\
\hline Mycophenolate mofetil & 1 & 7 & 0 & 1 & 0 & 0 & \\
\hline Antifibrotics & $11^{\pi}$ & & & & & & \\
\hline Pirfenidone & 7 & $4(3-24)$ & 0 & 3 & 4 & 0 & \\
\hline Nintedanib & 7 & $44(1-80)$ & 0 & 3 & 4 & 0 & \\
\hline Bosentan & 1 & 15 & 0 & 0 & 1 & 0 & \\
\hline $\mathrm{N}$-acetylcysteine & 2 & $6(6-6)$ & 0 & 0 & 2 & 0 & \\
\hline No ILD therapy & 7 & $54(2-174)$ & 0 & 0 & 7 & 0 & \\
\hline Lung transplantation & 4 & $50(35-52)$ & \multicolumn{3}{|c|}{2 patients alive, 2 patients dead } & Pancytopenia & $2(50)$ \\
\hline
\end{tabular}

Data are presented as $\mathrm{n}, \mathrm{n}(\%)$ or median (min-max). ILD: interstitial lung disease. ${ }^{\#}$ : serious hepatic or haematological adverse events; ${ }^{\text {ก: }}$ one patient may have received multiple therapies.

\section{Discussion}

In this large series, we show that patients with ILD and RTEL1 mutations present with various pulmonary and extrapulmonary phenotypes, including Sarc and RA-ILD, although haematological features are rare. In addition, we have shown that RTEL1 is expressed in the lung, mostly in epithelial cells and alveolar macrophages, without evidence of a role for the RTEL1 mutations in modulating this expression.

After being involved in Hoyeraal-Hreidarsson syndrome, a severe form of DC, heterozygous mutations of RTEL1 were reported in 5-9\% of familial ILD by three independent research groups in 2014 [15-17], albeit with sparse clinical data (table 5). A series of 10 patients who underwent lung transplantation was published thereafter, but detailed clinical data was not provided. More recently, clinical data about 14 patients with familial pulmonary fibrosis carrying a RTEL1 mutation were reported and results are comparable to this series [7]. Indeed UIP (82.6\%) was the most frequent pattern and IPF (74\%) was the most frequent ILD associated with RTEL1 mutation. However, UnF, chronic HP, CTD-ILD or PPFE may be diagnosed even in the same family [7].

Whether there could be a specific pulmonary phenotype associated with TRG mutation is a matter of discussion. PPFE has been reported in 13 patients with a TRG mutation [29, 30], including in two patients

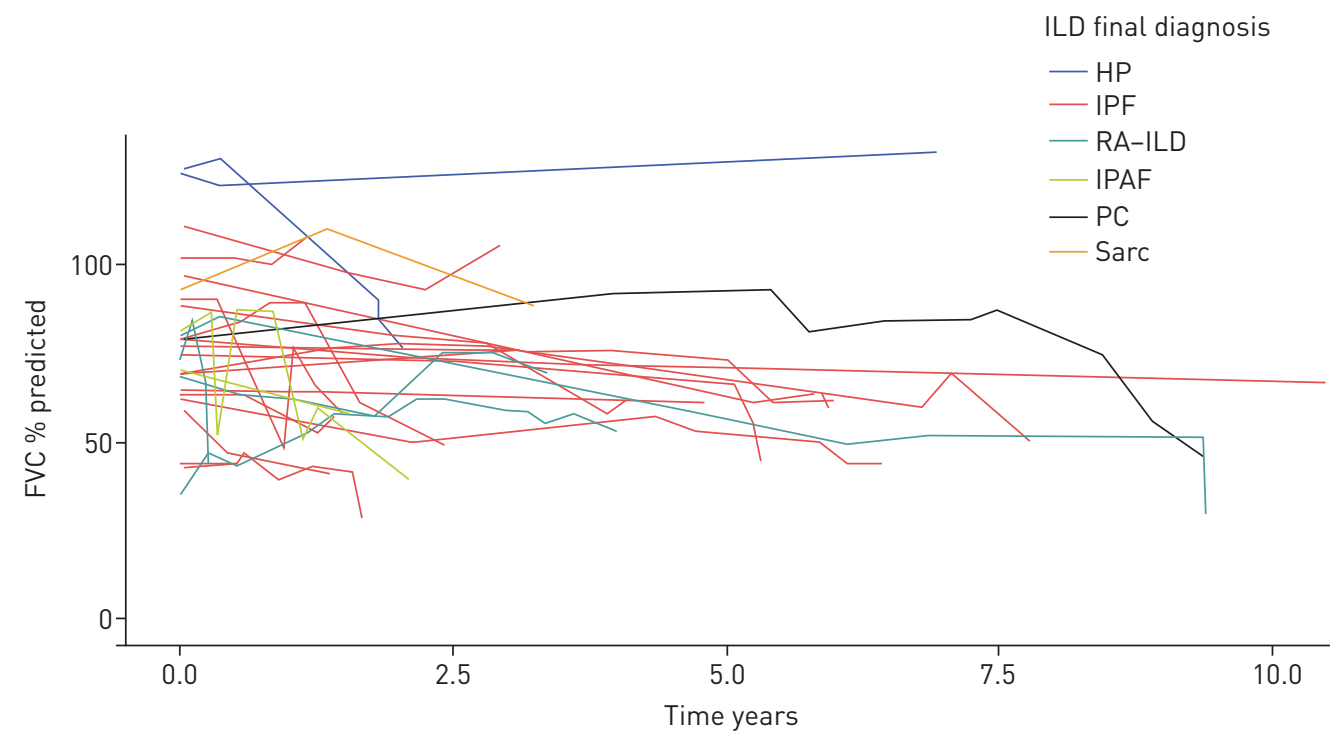

FIGURE 3 Individual evolution of forced vital capacity (FVC) of patients with interstitial lung disease (ILD) associated with regulator of telomere length 1 (RTEL1) mutation according to pulmonary diagnosis. HP: hypersensitivity pneumonitis; IPF: idiopathic pulmonary fibrosis; RA: rheumatoid arthritis; IPAF: interstitial pneumonia with autoimmune features; PC: pneumoconiosis; Sarc: sarcoidosis. 
TABLE 4 Factors at the time of diagnosis associated with transplant-free survival on univariate analysis

\begin{tabular}{|c|c|c|}
\hline Variable & Hazard ratio $(95 \% \mathrm{CI})$ & p-value \\
\hline $\operatorname{Age}^{\#}$ & $1.03(0.97-1.09)$ & 0.34 \\
\hline Smoking status & $1.04(0.82-1.32)$ & 0.74 \\
\hline Generation" & $1.98(0.62-6.36)$ & 0.25 \\
\hline Computed tomography pattern ${ }^{+}$ & $0.66(0.13-3.27)$ & 0.61 \\
\hline Final diagnosis of IPF & $2.11(0.78-5.69)$ & 0.14 \\
\hline FVC $^{\S} \%$ predicted & $0.88(0.80-0.97)$ & 0.009 \\
\hline D.co§ $\%$ predicted & $0.96(0.87-1.05)$ & 0.36 \\
\hline
\end{tabular}

FVC: forced vital capacity; DLCO: diffusing lung capacity for carbon monoxide. " : impact of an increase of 1 year on survival; " : first generation with interstitial lung disease (ILD) versus second or third generation with ILD $;{ }^{+}$: typical usual interstitial pneumonia (UIP)/probable UIP; ${ }^{\S}$ : impact of a decrease of $1 \%$ on survival.

with a RTEL1 mutation [7]. None of the patients from the present series presented PPFE. TRG mutations have also been associated with combined pulmonary fibrosis and emphysema and with familial emphysema in female smokers [31]. In a cohort of 292 patients with severe chronic obstructive pulmonary disease (COPD), three patients (1\%) were found to have TERT mutations [32]. We observed a $24 \%$ prevalence of combined pulmonary fibrosis and emphysema in the present series, a prevalence which is in accordance with that commonly observed in IPF cohorts [33].

TABLE 5 Reported patients with interstitial lung disease (ILD) and regulator of telomere length 1 (RTEL1) mutations

\begin{tabular}{|c|c|c|c|c|c|c|c|c|}
\hline \multirow[t]{2}{*}{ Characteristic } & \multicolumn{8}{|c|}{ Author and reference } \\
\hline & $\begin{array}{l}\text { Deng } \\
{[10]}\end{array}$ & $\begin{array}{c}\text { Speckmann } \\
{[14]}\end{array}$ & $\begin{array}{c}\text { Cogan } \\
\text { [17] }\end{array}$ & $\begin{array}{c}\text { Stuart }^{\#} \\
\text { [15] }\end{array}$ & $\begin{array}{l}\text { Newton } \# \\
\text { [7] }\end{array}$ & $\begin{array}{l}\text { Petrovski } \\
\text { [18] }\end{array}$ & $\begin{array}{c}\text { This series } \\
\text { (incl. }[16,20] \text { ) }\end{array}$ & Total \\
\hline Family testing" & $\begin{array}{c}\text { One DC case } \\
\text { report }\end{array}$ & $\begin{array}{c}\text { One DC } \\
\text { series }\end{array}$ & $9 / 188$ & $5 / 99$ & & $10 / 262^{+}$ & $17 /(151+101)^{\S}$ & 38 \\
\hline Patients & 1 & 1 & 49 & 16 & 14 & 10 & 35 & 110 \\
\hline Age at diagnosis years & 58 & 0.7 & 64.8 & 65.9 & 60.0 & UNK & 53.2 & 60.0 \\
\hline Male & $1(100)$ & $0(0)$ & 29 (59) & $7(44)$ & $8(57)$ & $8(80)$ & $21(60)$ & $67(61)$ \\
\hline Anticipation & UNK & UNK & UNK & Yes & Yes & UNK & Maybe & \\
\hline Ever smoker & UNK & $0(0)$ & 19 (39) & $7(44)$ & $7(50)$ & UNK & $25(71)$ & \\
\hline \multicolumn{9}{|l|}{ Pulmonary diagnosis } \\
\hline IPF & UNK & UNK & $47(96)$ & $>8(>50)$ & $3(30)^{f}$ & $10(100)$ & $20(57)$ & 80 (73) \\
\hline IPAF or CTD-ILD & UNK & UNK & UNK & UNK & $1(10)^{f}$ & 0 & $7(20)$ & $8(7)$ \\
\hline UnF & UNK & UNK & UNK & UNK & $3(30)^{f}$ & 0 & $4(11)$ & $7(6)$ \\
\hline Chronic HP & UNK & UNK & UNK & UNK & $1(10)^{f}$ & 0 & $2(6)$ & $3(3)$ \\
\hline Sarcoidosis & UNK & UNK & UNK & UNK & $0(0)$ & 0 & $1(3)$ & $1(1)$ \\
\hline PC & UNK & UNK & UNK & UNK & $0(0)$ & 0 & $1(3)$ & $1(1)$ \\
\hline PPFE & UNK & UNK & UNK & UNK & $2(20)^{f}$ & 0 & 0 & $2(2)$ \\
\hline Lung cancer & 0 & 0 & UNK & $2(13)$ & $2(14)$ & 0 & $1(3)$ & $3(3)$ \\
\hline Haematological disease & 0 & $1(100)$ & UNK & $5(31)$ & $5(36)$ & UNK & $7(20)$ & $13(12)$ \\
\hline Thrombocytopenia & 0 & $1(100)$ & UNK & $1(6)$ & $0(0)$ & UNK & $4(11)$ & $5(5)$ \\
\hline Macrocytosis & 0 & $1(100)$ & UNK & $2(13)$ & $4(29)$ & UNK & $5(14)$ & $10(9)$ \\
\hline Anaemia & 0 & $1(100)$ & UNK & $3(19)$ & $3(21)$ & UNK & $5(14)$ & $9(8)$ \\
\hline Hepatic disease & 0 & 0 & UNK & $1(6)$ & $1(7)$ & UNK & $4(11)$ & $5(5)$ \\
\hline
\end{tabular}

Data are presented as $\mathrm{n}$ or $\mathrm{n}(\%)$. When available for analysis, all available data from the manuscripts were retrieved and considered individually. DC: dyskeratosis congenita; UNK: unknown; IPF: idiopathic pulmonary fibrosis; IPAF: interstitial pneumonia with autoimmune features; CTD: connective tissue disease; UnF: unclassifiable fibrosis; HP: hypersensitivity pneumonitis; PC: pneumoconiosis; PPFE: pleuroparenchymal fibroelastosis. \#: the patients reported by STUART et al. [15] were considered to be extensively reported by NEWTON et al. [7] and as such none of the patients reported by STUART were included in the total column; ${ }^{\text {: }}$ : data on testing is recorded as number of mutated families/number of families tested (where available) unless otherwise stated; ${ }^{+}$: including sporadic ILD that have been evaluated for lung transplantation at a mean age of $63.2 \pm 8.2$ years; ${ }^{\S}$ : 151 monogenic and 101 rheumatoid arthritis (RA)-ILD, including suspected monogenic ILD included probands with familial ILD or short telomere syndrome without telomerase reverse transcriptase (TERT) or telomerase RNA component (TERC) pathogenic mutation; ${ }^{f}$ : only ten patients had a clearly defined pulmonary diagnosis. 

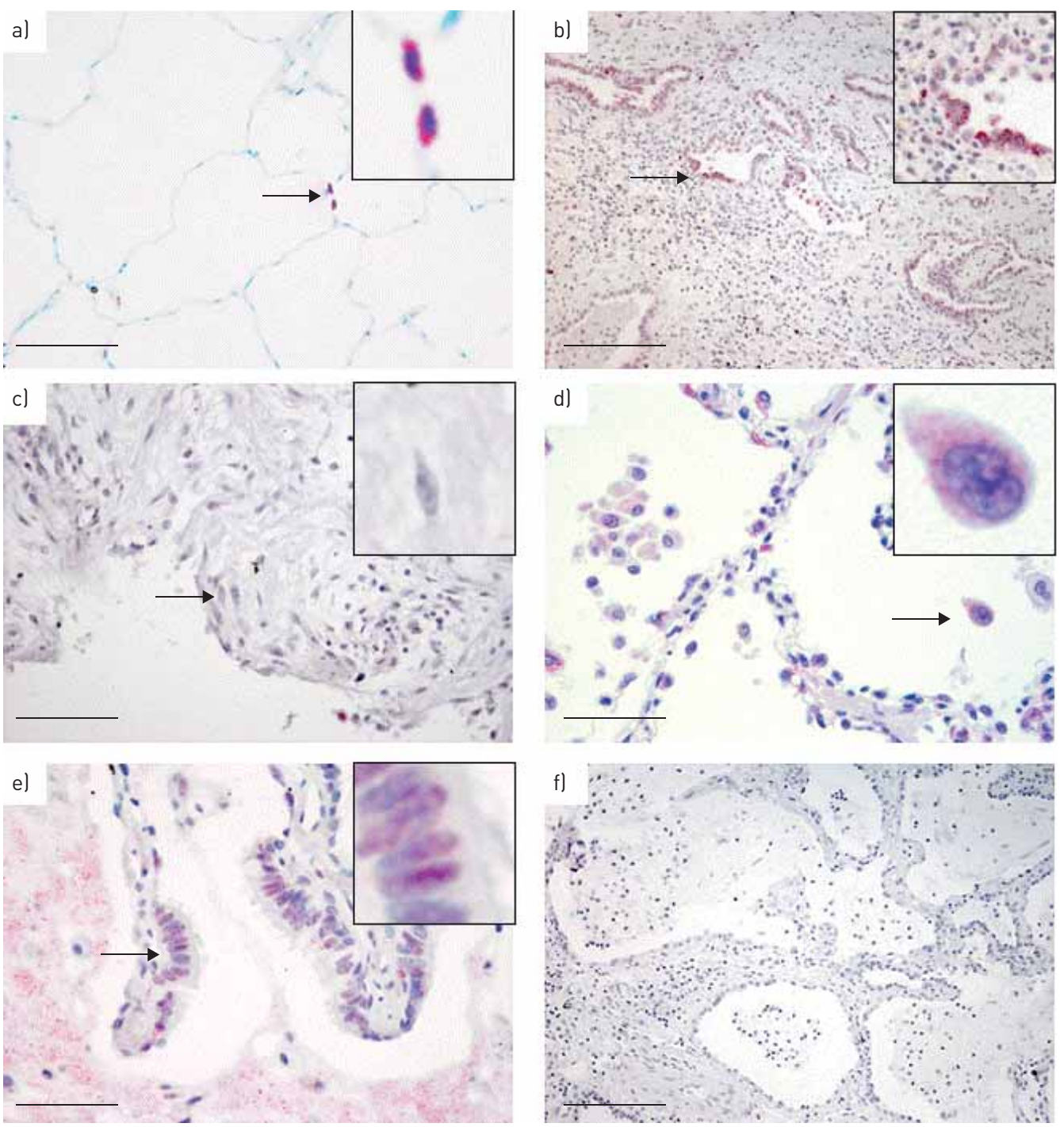

FIGURE 4 Immunohistochemical regulator of telomere length 1 (RTEL1) staining in the lung as follows: a) normal lung ( $\times 10$ magnification; insert $\times 40$ magnification; scale bar $24 \mu \mathrm{m})$; b) idiopathic pulmonary fibrosis (IPF; $\times 10$ magnification; insert $\times 40$ magnification; scale bar $24 \mu \mathrm{m})$; c) fibroblastic foci $(\times 40$ magnification insert $\times 160$ magnification; scale bar $6 \mu \mathrm{m})$; d) normal area and e) honeycomb cyst from an IPF lung ( $\times 40$ magnification; insert $\times 160$ magnification; scale bar $6 \mu \mathrm{m})$; $)$ control of isotype $(\times 10$ magnification; scale bar $24 \mu \mathrm{m})$. RTEL1 was detected in the cytoplasm and the nucleus of bronchial epithelial cells, alveolar macrophages and in alveolar Type-2 epithelial cells (arrows). RTEL1 was not detected in fibroblastic foci or endothelial cells.

This case series also reports heterogeneous evolution with a mean decline in FVC of $140.5 \mathrm{~mL} \cdot \mathrm{year}^{-1}$. For instance, two patients with NSIP presented pulmonary improvement with steroids that persisted after 18 months of treatment. These observations suggest that alongside the aetiology and the genetic background, the pattern of ILD should be considered in the therapeutic decision. However, this suggestion should be supported by future studies. Concerning disease progression, NewTon et al. [7] reported a $300 \mathrm{~mL} \cdot \mathrm{year}^{-1}$ decline in FVC in 71 TRG mutation carriers, whatever the gene or the pulmonary diagnosis (i.e. IPF or not), which is very similar to the decline we measured in one series $\left(314.5 \pm 107.6 \mathrm{~mL} \cdot\right.$ year $\left.^{-1}\right)$ [34]. Interestingly, post-hoc analysis of randomised clinical trials showed that patients with a rare variant of TERT, PARN, TERC, or RTEL1 had a more rapid decline in predicted FVC than patients without a single variant ( $1.66 \%$ versus $0.83 \%$ per month). Furthermore, it was shown that pirfenidone reduced the decline in FVC of patients with rare variants of TERT, PARN, TERC, or RTEL1 [35]. $T E R T$ and TERC mutations have also been shown to reduce transplant-free survival times and to increase the number of haematological complications after lung transplantation [26, 36, 37].

Altogether, hematological abnormalities and liver involvement were reported in nearly $25 \%$ and $10 \%$ of patients, respectively, suggesting RTEL1-associated ILD patients are less prone to displaying the 
TABLE 6 Main characteristics of interstitial lung disease (ILD) subjects from our database with heterozygous telomerase reverse transcriptase (TERT), telomerase RNA component (TERC), or regulator of telomere length 1 (RTEL1) mutations

\begin{tabular}{|c|c|c|c|c|}
\hline \multirow[t]{2}{*}{ Characteristic } & \multicolumn{3}{|c|}{ Mutation } & \multirow[t]{2}{*}{ p-value } \\
\hline & RTEL1 & TERT & TERC & \\
\hline Patients & 35 & 34 & 6 & \\
\hline Age at diagnosis years & $53(28-81)$ & $58(36-79)$ & $46(39-55)$ & 0.82 \\
\hline Male & $21(60)$ & $24(71)$ & $4(67)$ & 0.36 \\
\hline Number of ILDs per family & $3(1-5)$ & $1(1-3)$ & $1(1-3)$ & 0.54 \\
\hline Smoking or fibrogenic exposure & $29(83)$ & $24(71)$ & $4(67)$ & 0.19 \\
\hline Typical or probable UIP pattern by CT & $25(71)$ & 20 (59) & $3(50)$ & 0.21 \\
\hline IPF diagnosis & $20(57)$ & $21(62)$ & $3(50)$ & 0.80 \\
\hline \multicolumn{5}{|l|}{ Extra-pulmonary signs } \\
\hline Premature hair graying & $8(23)$ & $9(26)$ & 2 (33) & 0.64 \\
\hline Haematological disease & $7(20)$ & $21(62)$ & $3(50)$ & 0.001 \\
\hline Thrombocytopenia & $4(11)$ & $17(50)$ & $3(50)$ & 0.001 \\
\hline Macrocytosis & $5(14)$ & $13(38)$ & $3(50)$ & 0.06 \\
\hline Anaemia & $5(14)$ & $5(15)$ & $1(17)$ & 0.93 \\
\hline Hepatic disease & $4(11)$ & $12(35)$ & $4(67)$ & 0.005 \\
\hline Telomere length kb & $6.5(4.4-10.8)$ & 7.33 (3.78-10.6) & $4.5(4.3-5.5)$ & 0.05 \\
\hline \multicolumn{5}{|c|}{$\begin{array}{l}\text { Data are reported as } \mathrm{n}, \mathrm{n}(\%) \text {, or median (min-max). UIP: usual interstitial pneumonia; CT: computed } \\
\text { tomography; IPF: idiopathic pulmonary fibrosis. \# : patients with RTEL } 1 \text { mutations were compared to the } \\
\text { whole group of patient carriers of TERT or TERC mutations by the Mann-Whitney U-test or the Chi-squared } \\
\text { test. }\end{array}$} \\
\hline
\end{tabular}

extrapulmonary phenotypes evidenced in other TRG-associated ILD patients (table 6). Indeed, ILD patients from this series presented less frequent low platelet counts and less frequent red blood cell macrocytosis compared to previously reported ILD patients who were carriers of TERT or TERC mutations (table 6) [26].

It confirms the results reported by NEwTON et al. [7] where, unlike three out of seven patients with TERC mutations, none of the 14 patients with RTEL1 mutations presented thrombocytopenia nor myelodysplastic syndrome. Furthermore, the bone marrow suppression noted with cyclophosphamide and after lung transplant in the current series may be related to a side effect of well-known cytotoxic medications rather than to an RTEL1-related event. Moreover, no patients with haematological or hepatic disease without ILD were reported within these families. However, a recent study identified a cohort of patients with bone marrow failure and myeloid neoplasms carrying germinal RTEL1 mutations, including two pedigrees with pulmonary fibrosis and haematological diseases [38].

The pathophysiology of pulmonary fibrosis in carriers of RTEL1 mutations remains unknown. Even though RTEL1 is known to regulate telomere length, the exact mechanism by which specific mutations cause telomere shortening is the topic of ongoing research [39]. Telomere dysfunction causes stem cell failure in the bone marrow and has been linked to alveolar epithelial senescence in the lung [40]. We showed that RTEL1 was expressed in normal and fibrotic lungs, including in patients who were carriers of TERT or RTEL1 mutations. RTEL1 was detected in epithelial cells but not in fibroblastic foci, supporting the hypothesis that RTEL1 alteration is involved in alveolar epithelial dysfunction, a fundamental element in lung fibrosis pathophysiology [41].

Telomere length was shortened in most of the patients, although some had a normal telomere length as assessed by Southern blot. However, telomere length and analysis of telomerase activity may be difficult to interpret in older adult patients. In one study, $15 \%$ of the TERT mutation carriers had a normal telomere length [42], while half of the $>60$ years old patients with pulmonary fibrosis and TERT, TERC or RTEL1 mutation presented with above 10th percentile $(>10$ th) telomere length in another study [43]. We assessed telomere length by Southern blot, a method that requires large amounts of DNA but may be performed on stored material. Southern blot and flow-FISH (fluorescent in-situ hybridisation) analysis provide comparable results for telomere length, but flow-FISH requires fresh or fresh-frozen lymphocytes which were unavailable in this retrospective case series [44]. Compared to Southern blot, quantitative PCR requires a lesser amount of DNA, but telomere length analysis may show a coefficient of variation of up to 25\% [43-45]. Lastly, Southern blot analysis only provides a mean telomere length and does not provide inter-chromosomal and inter-cellular heterogeneity of telomere length that may be more accurately related to telomerase dysfunction 
induced by TRG mutations. However, all mutations were considered as pathogenic according to the absence or very low frequency of these RTEL1 variations in the general population, the impact of the mutation (already associated disease mutations, variations leading to premature stop codon, splicing mutations etc), in silico analysis and, when available, co-segregation of the mutation and telomere length [19].

This series is limited by its retrospective nature and the absence of some CT scans and PFT results. Indeed, we were not able to retrieve any CT scans for four patients and the diagnosis of unspecified pulmonary fibrosis reported in the medical records could not be confirmed. Furthermore, we should assume an incomplete understanding of these families and the history of family members may easily miss liver and haematologic abnormalities in family members without ILD. Given the retrospective nature of the investigation, RTEL1 mutations do not necessarily affect outcome variables and the phenotypes described herein should actually be considered as an association.

We conclude that RTEL1 mutations are most frequently associated with IPF, but that other lung phenotypes may be observed. Extra-respiratory manifestations, mainly haematologic and hepatic, are similar to those associated with other TRG mutations, although less frequent. Such phenotypic heterogeneity requires a thorough evaluation of RTEL1-associated ILD patients in order to define tailored therapeutic strategies $[46,47]$.

Collaborators: Isabelle Callebaut (UPMC UMR CNRS 7590 Paris); Smail Amar, Eline Magois (CHU d'Amiens Amiens); Aurélie Plessier (Hôpital Beaujon Clichy); Pierre-Yves Brillet, Marianne Kambouchner, Dominique Valeyre, Yurdagul Uzunhan (Hôpital Avicenne Bobigny); Evguenia Dobrinskikh (University of Colorado Denver USA); Sophie Park (CHU Grenoble Alpes Grenoble); Anas Mehdaoui (Hôpital Eure Seine Evreux); Reza Azarian (Hôpital André Mignot Le Chesnay); Nicolas Pottier, Benoit Wallaert (CHRU de Lille Lille); Chantal-Michele Bertocchi (Centre hospitalier Annecy Genevois Metz-Tessy); Kaïs Ahmad (Hôpital Louis Pradel Lyon); Jacques Piquet (Centre hospitalier Intercommunal Le Raincy-Montfermeil Montfermeil); Arnaud Bourdin (CHRU de Montpellier Montpellier); Farida Skander (CHU Oran Oran); Claire Danel, Gaelle Dauriat, Aurelien Justet, Camille Taillé (Hôpital Bichat Paris); Isabelle Honoré (Hôpital Cochin Paris); Flore Sicre de Fontbrune (Hôpital Saint Louis Paris); Sandrine Hirschi, Armelle Schuller (Hôpitaux Universitaires de Strasbourg Strasbourg); Serge Amselem, Nadia Nathan, Annick Clement (Hôpital Trousseau Paris).

Conflict of interest: R. Borie reports grants and personal fees from Roche, personal fees from Boerhinger Ingelheim and Savapharma, outside the submitted work. D. Bouvry has nothing to disclose. V. Cottin reports personal fees for consultancy, lecturing and travel to medical meetings from Actelion and Roche, personal fees for development of educational presentations, consultancy, lecturing and travel to medical meetings from Boehringer Ingelheim, personal fees for consultancy from Bayer and GSK, personal fees for adjudication committee work from Gilead, personal fees for consultancy and travel to medical meetings from MSD, personal fees for consultancy and lecturing from Novartis and Sanofi, institutional grants from Boehringer Ingelheim and Roche, personal fees for data and safety monitoring board work from Promedior and Celgene, personal fees for consultancy and data and safety monitoring board work from Galapagos, outside the submitted work. C. Gauvain has nothing to disclose. A. Cazes has nothing to disclose. M-P. Debray reports personal fees from Boehringer-Ingelheim, and reimbursement for travel and accommodation for medical meeting for Guerbet and Roche, outside the submitted work. J. Cadranel has nothing to disclose. P. Dieude has nothing to disclose. T. Degot reports personal fees for expert testimony in ILD and travel reimbursement for the Congress CPLF 2018 in Lyon from Boerhinger Ingelheim France, and personal fees for expert testimony in ILD from Roche France, outside the submitted work. S. Dominique reports personal fees from Roche and Boehringer Ingelheim, outside the submitted work. A.S. Gamez has nothing to disclose. M. Jaillet has nothing to disclose. P-A. Juge has nothing to disclose. A. Londono-Vallejo has nothing to disclose. A. Mailleux has nothing to disclose. H. Mal has nothing to disclose. C. Boileau has nothing to disclose. C. Menard has nothing to disclose. H. Nunes has nothing to disclose. G. Prevot has nothing to disclose. S. Quetant has nothing to disclose. P. Revy has nothing to disclose. J. Traclet has nothing to disclose. L. Wemeau-Stervinou reports personal fees and non-financial support from Boehringer-Ingelheim and Roche, personal fees from Bristol-Myers-Squibb and Jansen-Cilag, outside the submitted work. M. Wislez has nothing to disclose. C. Kannengiesser has nothing to disclose. B. Crestani reports grants for research and personal fees for development of educational presentations, consultancy, lecturing and travel to medical meetings from Boehringer Ingelheim, grants for research and personal fees for consultancy, lecturing and travel to medical meetings from Roche, personal fees for consultancy and lecturing from Sanofi and Apellis, personal fees for consultancy, lecturing and travel to medical meetings from AstraZeneca, and research grants from MedImmune, outside the submitted work.

Support statement: This work was supported by le Fonds de Recherche en Santé Respiratoire et de la Fondation du Souffle, la Chancellerie des Universités de Paris (legs Poix), and a grant from Roche. Funding information for this article has been deposited with the Crossref Funder Registry.

\section{References}

1 Kropski JA, Pritchett JM, Zoz DF, et al. Extensive phenotyping of individuals at risk for familial interstitial pneumonia reveals clues to the pathogenesis of interstitial lung disease. Am J Respir Crit Care Med 2015; 191: 417-426.

2 Mathai SK, Newton CA, Schwartz DA, et al. Pulmonary fibrosis in the era of stratified medicine. Thorax 2016; 71: $1154-1160$.

3 Armanios M, Blackburn EH. The telomere syndromes. Nat Rev Genet 2012; 13: 693-704.

4 Kropski JA, Mitchell DB, Markin C, et al. A novel dyskerin (DKC1) mutation is associated with familial interstitial pneumonia. Chest 2014; 146: e1-e7.

5 Alder JK, Stanley SE, Wagner CL, et al. Exome sequencing identifies mutant TINF2 in a family with pulmonary Fibrosis. Chest 2015; 147: 1361-1368. 
6 Stanley SE, Gable DL, Wagner CL, et al. Loss-of-function mutations in the RNA biogenesis factor NAF1 predispose to pulmonary fibrosis-emphysema. Sci Transl Med 2016; 8: 351 ral07.

7 Newton CA, Batra K, Torrealba J, et al. Telomere-related lung fibrosis is diagnostically heterogeneous but uniformly progressive. Eur Respir J 2016; 48: 1710-1720.

8 Vannier JB, Pavicic-Kaltenbrunner V, Petalcorin MI, et al. RTEL1 dismantles T loops and counteracts telomeric G4-DNA to maintain telomere integrity. Cell 2012; 149: 795-806.

9 Le Guen T, Jullien L, Touzot F, et al. Human RTEL1 deficiency causes Hoyeraal-Hreidarsson syndrome with short telomeres and genome instability. Hum Mol Genet 2013; 22: 3239-3249.

10 Deng Z, Glousker G, Molczan A, et al. Inherited mutations in the helicase RTEL1 cause telomere dysfunction and Hoyeraal-Hreidarsson syndrome. Proc Natl Acad Sci USA 2013; 110: E3408-E3416.

11 Ballew BJ, Yeager M, Jacobs K, et al. Germline mutations of regulator of telomere elongation helicase 1, RTEL1, in Dyskeratosis congenita. Hum Genet 2013; 132: 473-480.

12 Ballew BJ, Joseph V, De S, et al. A recessive founder mutation in regulator of telomere elongation helicase 1, RTEL1, underlies severe immunodeficiency and features of Hoyeraal Hreidarsson syndrome. PLoS Genet 2013; 9: e1003695.

13 Cardoso SR, Ellison ACM, Walne AJ, et al. Myelodysplasia and liver disease extend the spectrum of RTEL1 related telomeropathies. Haematologica 2017; 102: e293-e296.

14 Speckmann C, Sahoo SS, Rizzi M, et al. Clinical and molecular Heterogeneity of RTEL1 deficiency. Front Immunol 2017; 8: 449

15 Stuart BD, Choi J, Zaidi S, et al. Exome sequencing links mutations in PARN and RTEL1 with familial pulmonary fibrosis and telomere shortening. Nat Genet 2015; 47: 512-517.

16 Kannengiesser C, Borie R, Menard C, et al. Heterozygous RTEL1 mutations are associated with familial pulmonary fibrosis. Eur Respir J 2015; 46: 474-485.

17 Cogan JD, Kropski JA, Zhao M, et al. Rare variants in RTEL1 are associated with familial interstitial pneumonia. Am J Respir Crit Care Med 2015; 191: 646-655.

18 Petrovski S, Todd JL, Durheim MT, et al. An exome sequencing study to assess the role of rare genetic variation in pulmonary fibrosis. Am J Respir Crit Care Med 2017; 196: 82-93.

19 Richards S, Aziz N, Bale S, et al. Standards and guidelines for the interpretation of sequence variants: a joint consensus recommendation of the American College of Medical Genetics and Genomics and the Association for Molecular Pathology. Genet Med 2015; 17: 405-424.

20 Juge PA, Borie R, Kannengiesser C, et al. Shared genetic predisposition in rheumatoid arthritis-interstitial lung disease and familial pulmonary fibrosis. Eur Respir J 2017; 49; 1602314.

21 Raghu G, Collard HR, Egan JJ, et al. An official ATS/ERS/JRS/ALAT statement: idiopathic pulmonary fibrosis: evidence-based guidelines for diagnosis and management. Am J Respir Crit Care Med 2011; 183: 788-824.

22 Travis WD, Costabel U, Hansell DM, et al. An official American Thoracic Society/European Respiratory Society statement: update of the international multidisciplinary classification of the idiopathic interstitial pneumonias. Am J Respir Crit Care Med 2013; 188: 733-748.

23 Lynch DA, Sverzellati N, Travis WD, et al. Diagnostic criteria for idiopathic pulmonary fibrosis: a Fleischner Society white paper. Lancet Respir Med 2018; 6: 138-153.

24 Taille C, Grootenboer-Mignot S, Boursier C, et al. Identification of periplakin as a new target for autoreactivity in idiopathic pulmonary fibrosis. Am J Respir Crit Care Med 2011; 183: 759-766.

25 Schertzer M, Jouravleva K, Perderiset M, et al. Human regulator of telomere elongation helicase 1 (RTEL1) is required for the nuclear and cytoplasmic trafficking of pre-U2 RNA. Nucleic Acids Res 2015; 43: 1834-1847.

26 Borie R, Tabeze L, Thabut G, et al. Prevalence and characteristics of TERT and TERC mutations in suspected genetic pulmonary fibrosis. Eur Respir J 2016; 48: 1721-1731.

27 Toyoda I, Matsuyama Y, Ohashi Y. Estimation and comparison of rates of change in repeated-measures studies with planned dropout. Control Clin Trials 2001; 22: 620-638.

28 Walne AJ, Vulliamy T, Kirwan M, et al. Constitutional mutations in RTEL1 cause severe dyskeratosis congenita. Am J Hum Genet 2013; 92: 448-453.

29 Nunes H, Jeny F, Bouvry D, et al. Pleuroparenchymal fibroelastosis associated with telomerase reverse transcriptase mutations. Eur Respir J 2017; 49; 1602022.

30 Newton CA, Batra K, Torrealba J, et al. Pleuroparenchymal fibroelastosis associated with telomerase reverse transcriptase mutations. Eur Respir J 2017; 49; 1700696.

31 Nunes H, Monnet I, Kannengiesser C, et al. Is telomeropathy the explanation for combined pulmonary fibrosis and emphysema syndrome? Report of a family with TERT mutation. Am J Respir Crit Care Med 2014; 189: 753-754

32 Stanley SE, Chen JJ, Podlevsky JD, et al. Telomerase mutations in smokers with severe emphysema. J Clin Invest 2015; 125: 563-570.

33 Cottin V. Combined pulmonary fibrosis and emphysema: bad and ugly all the same? Eur Respir J 2017; 50; 1700846 .

34 Justet A, Thabut G, Manali E, et al. Safety and efficacy of pirfenidone in patients carrying telomerase complex mutation. Eur Respir J 2018; 51; 1701875.

35 Dressen A, Abbas AR, Cabanski C, et al. Analysis of protein-altering variants in telomerase genes and their association with MUC5B common variant status in patients with idiopathic pulmonary fibrosis: a candidate gene sequencing study. Lancet Respir Med 2018; 6: 603-614.

36 Borie R, Kannengiesser C, Hirschi S, et al. Severe hematologic complications after lung transplantation in patients with telomerase complex mutations. J Heart Lung Transplant 2015; 34: 538-546.

37 Silhan LL, Shah PD, Chambers DC, et al. Lung transplantation in telomerase mutation carriers with pulmonary fibrosis. Eur Respir J 2014; 44: 178-187.

38 Marsh JCW, Gutierrez-Rodrigues F, Cooper J, et al. Heterozygous RTEL1 variants in bone marrow failure and myeloid neoplasms. Blood Adv 2018; 2: 36-48.

39 Frizzell A, Nguyen JH, Petalcorin MI, et al. RTEL1 inhibits trinucleotide repeat expansions and fragility. Cell Rep 2014; 6: 827-835.

40 Armanios M. Telomeres and age-related disease: how telomere biology informs clinical paradigms. J Clin Invest 2013; 123: 996-1002. 
41 Selman M, Pardo A. Role of epithelial cells in idiopathic pulmonary fibrosis: from innocent targets to serial killers. Proc Am Thorac Soc 2006; 3: 364-372.

42 de Leon A D, Cronkhite JT, Katzenstein AL, et al. Telomere lengths, pulmonary fibrosis and telomerase (TERT) mutations. PLoS One 2010; 5: e10680.

43 Alder JK, Hanumanthu VS, Strong MA, et al. Diagnostic utility of telomere length testing in a hospital-based setting. Proc Natl Acad Sci USA 2018; 115: E2358-E2365.

44 Khincha PP, Dagnall CL, Hicks B, et al. Correlation of leukocyte telomere length measurement methods in patients with dyskeratosis congenita and in their unaffected relatives. Int J Mol Sci 2017; 18: E1765.

45 Townsley DM, Dumitriu B, Young NS. Danazol treatment for telomere diseases. N Engl J Med 2016; 375: 1095-1096.

46 Borie R, Kannengiesser C, Sicre de Fontbrune F, et al. Management of suspected monogenic lung fibrosis in a specialised centre. Eur Respir Rev 2017; 26: 160122.

47 Pelito AL, Zhang Y, Fingerlin TE, et al. Association between the MUC5B promoter polymorphism and survival in patients with idiopathic pulmonary fibrosis. JAMA 2013; 309: 2232-2239. 